DOI: http://dx.doi.org/10.23925/2176-2767.2020v67p11-41

Recebido em: 21/12/2019

Aprovado em: 29/02/2020

\title{
A FALSIFICAÇÃO DO JORNAL CATÓLICO O SÃO PAULO: UMA ANÁLISE DA REAÇÃO MIDIÁTICA À EDIÇÃO MEA CULPA (1982)
}

\section{THE FALSIFICATION OF CATHOLIC NEWSPAPER O SÃO PAULO: AN ANALYSIS OF THE MEDIATIC REACTION TO MEA CULPA EDITION (1982)}

\author{
FABIO LANZA* \\ JOSÉ WILSON ASSIS NEVES JÚNIOR** \\ RAÍSSA REGINA BRUGIATO RODRIGUES***
}

\section{RESUMO}

Este artigo analisa o processo de falsificação de uma edição do jornal católico $O$ São Paulo (1982). Enfoca-se na posterior reação midiática desencadeada pelo ocorrido, que gerou 154 documentos de revistas e jornais. Utilizou-se a análise documental, com contribuições da análise de discurso, sob um prisma histórico-processual das matrizes de Karl Mannheim e Norbert Elias. Apreendeu-se a intenção, do grupo responsável pela falsificação, de manipular os leitores do jornal para a vigilância e rejeição aos "comunistas", a reação midiática evidenciou a tentativa de cercear possibilidades de expressar-se de forma divergente ao cenário social e político da ditadura brasileira.

* Doutor em Ciências Sociais pela Pontifícia Universidade Católica (PUC-SP). Professor Associado no Departamento de Ciências Sociais da Universidade Estadual de Londrina. Coordenador do Laboratório de Estudos sobre as Religiões e Religiosidades da UEL. E- -mail: lanza1975@gmail.com .ORCID: https://orcid.org/0000-0003-3521-0035.

** Doutorando pelo Programa de Pós-Graduação em Ciências Sociais da Unesp/Marília. Bolsista Capes. Mestre e bacharel em Ciências Sociais pela UEL. Pesquisador vinculado ao Laboratório de Estudos sobre Religiões e Religiosidades (LERR-UEL). E-mail: nevesjr1991@gmail.com. ORCID: http://orcid.org/00000003-0692-0740.

*** Doutoranda pelo Programa de Pós-Graduação em Sociologia na Universidade Estadual de Londrina. Mestre, licenciada e bacharel em Ciências Sociais pela UEL. Pesquisadora vinculada ao Laboratório de Estudos sobre Religiões e Religiosidades (LERR-UEL). $\quad$ E-mail: $\quad$ raissaregina.uel@hotmail.com. $\quad$ ORCID: https://orcid.org/0000-0002-4048-2556. 
PALAVRAS-CHAVE: Ditadura Militar (1964-1985); Jornal Católico O São Paulo; Pensamento Conservador; Reação Midiática.

\begin{abstract}
This paper analyzes the falsification process of one edition of the catholic newspaper $O$ São Paulo (1982). Focuses on mediatic reaction posterior to the fact, that generated 154 documents from magazines and newspapers. Were utilized the documental analysis, with contributions from discourse analysis, under the historical-processual perspective of Karl Mannheim and Norbert Elias matrix. The intention, of the group responsible for the falsification, to manipulated the newspaper lectors for vigilance and rejection to "communists" was apprehended, the mediatic reaction evidenced the attempted to retrench the possibilities to express distinguish perspectives of Brazilian military dictatorship social-political reality.
\end{abstract}

KEYWORDS: Military Dictatorship (1964-1985); Catholic newspaper O São Paulo; Conservative Thought; Media Reaction.

\title{
Introdução ${ }^{1}$
}

A presente pesquisa desenvolveu-se partindo da noção da existência de um processo de pensamento conservador brasileiro que se desenvolveu de forma interligada ao cenário histórico, social, político e cultural do país, espraiando-se aos mais diversos âmbitos da vida social e engendrando variadas formas de expressão, ações, estratégias, entre outros, em grupos sociais que dialogam com formas de pensamento conservadoras e fatores objetivos correspondentes ao período histórico em que ambos atuam.

Abordando-se alguns de seus elementos, procurou-se trabalhar com a compreensão de que, entre os grupos de indivíduos que dialogam com noções religiosas pertencentes ao catolicismo, entre outras ações e consequências, o referido processo gerou a falsificação, no ano de 1982,

\footnotetext{
${ }^{1}$ Este artigo é resultado do trabalho em equipe do Laboratório de Estudos sobre Religiões e Religiosidades da UEL PR e de parte da dissertação "Permanências do conservadorismo brasileiro no processo de redemocratização na década de 1980: estudo d'O São Paulo e da edição falsificada mea culpa" (RODRIGUES, 2018). O texto foi revisado e ampliado em co-autoria para esta publicação.
} 
de uma edição do jornal católico O São Paulo (JOSP), ${ }^{2}$ meio de comunicação oficial da Arquidiocese de São Paulo, sede de maior expressão do catolicismo brasileiro.

O semanário católico JOSP veiculava, no período ${ }^{3}$ da falsificação, conteúdos de relevância social, o que possibilitou considerar suas publicações como inseridas em uma perspectiva de resistência à ditadura militar, o que desencadeou anteriormente, inclusive, o processo de censura prévia em suas publicações, entre 1972 e 1978. Na conjuntura em que se desenrolava a abertura política, houve, então, esse processo de elaboração de uma estratégia de falsificação reflexiva e intencional de uma edição do JOSP, intitulada Mea Culpa, que desencadeou posterior reação midiática impressa ${ }^{4}$ que acompanhou o progresso das investigações.

${ }^{2} \mathrm{O}$ semanário católico O São Paulo teve sua primeira edição publicada, de acordo com Lanza (2006), em 1956, e até o presente momento, ano de 2020, prossegue com suas publicações semanais.

${ }^{3}$ De acordo com Lanza (2006), as publicações do semanário podem ser pensadas em três períodos distintos, relacionados à gestão arcebispal da Arquidiocese de São Paulo em cada período: "O primeiro período, de 1956 a 1966, envolve a fase final do arcebispado de cardeal Motta, quando ocorreu a fundação d'O São Paulo, e parte do arcebispado de cardeal Agnelo Rossi. O segundo período, de 1966 a 1970, representou uma fase de transição entre a predominância conservadora e uma perspectiva progressista na gestão arcebispal da Arquidiocese de São Paulo, [...] coincidindo com a chegada do então bispo auxiliar Dom Paulo Evaristo Arns. O terceiro período, de 1970 a 1985, compreende o momento marcado pela ruptura ao apoio dado anteriormente aos governantes militares. Esta etapa esteve em consonância com a nomeação de Dom Arns à condição de arcebispo e cardeal. Este período se encerra com o fim da censura prévia ao semanário" (LANZA, 2006, p. 22).

${ }^{4}$ A despeito da compreensão da existência de um conjunto diverso de meios de comunicação em massa no período mencionado (como o rádio, jornais e televisão), no contexto da pesquisa desenvolvida, ao mobilizar o termo "reação midiática", referimo-nos às revistas e jornais impressos. Ao trabalhar com essa noção, têm-se em vista que, segundo Montero e Della Cava (1986), a partir da década de 1960, estando "o país [...] ligado de norte a sul via transportes e comunicações, [...] passa a existir um mercado consumidor de "bens culturais"” (MONTERO e DELLA CAVA, 1986, p. 65), e dessa forma os meios de comunicação disponíveis assumem grande 
Compreende-se, a partir de um diálogo com a teoria de Mannheim (1981) e com formulações de Elias (2002), que a falsificação se insere em um amplo processo histórico-configuracional de disputas entre estilos de pensamento, que se desenvolvem de forma dinâmica e processual, delineando-se a partir dos objetivos específicos das forças políticoeconômicas de grupos em sua determinada época e espaço. Suas formas, estratégias e manifestações assumem, nessa perspectiva, diversas características dos grupos de indivíduos que são seus portadores e cujo pensamento se insere em uma fase desse processo. Dessa forma, tendo diferentes atores em cada período, esse pensamento conservador carrega em si elementos conjunturais e os objetivos, na época, de seus grupos portadores.

O objeto da presente pesquisa considera, então, a existência de um diálogo entre os responsáveis pelo processo de elaboração e disseminação dessa edição falsificada com elementos de ordem objetiva, referentes à conjuntura político-social do período ditatorial, e as correntes de pensamento conservadoras, que, apesar de sua presença no desenrolar da ditadura, fazem parte de um processo mais amplo que não se restringe a essa época.

A partir dessa perspectiva buscou-se abordar uma das consequências desta manifestação do pensamento conservador (a estratégia de falsificação), que foi a reação midiática que se seguiu à falsificação e a abertura de espaços para a veiculação de notícias que se

importância para a produção de perspectivas que orientam a sociedade, sendo a mídia impressa um dos espaços mobilizado por Instituições Católicas para se comunicar com seus frequentadores e público leitor, no sentido de manter influências no processo de construção dessas formas de perceber o mundo e sua produção ideológica. 
chocavam com a censura imposta anteriormente aos meios de comunicação. Tendo em vista o projeto de pensamento conservador brasileiro que gerou o $\mathrm{Mea}$ Culpa, o objeto da presente pesquisa constituise em abordar e elaborar a caracterização dessa reação desencadeada pela falsificação da edição do JOSP, a partir dos documentos referentes aos jornais e revistas que acompanharam as investigações e trouxeram falas de membros da Arquidiocese $e^{5}$ e notícias sobre o andamento do inquérito.

$\mathrm{O}$ acesso aos materiais de pesquisa foi possível graças à disponibilização, pela Arquidiocese de São Paulo, de um arquivo de documentos censurados do JOSP (1972-1979) ${ }^{6}$ que continha um dossiê com o Mea Culpa (edição falsificada) e 154 matérias de revistas e jornais brasileiros e internacionais que acompanharam as investigações sobre os envolvidos. Essas matérias trazem relatos do andamento de investigações realizadas pelo serviço público e por serviços particulares contratados por membros da própria Arquidiocese, depoimentos de bispos, arcebispos, padres e representantes das chamadas direita e esquerda, com declarações, também, referentes às intenções de tais grupos que fomentaram todo o processo.

Foram mobilizadas, para a interpretação que se segue, orientações da análise com fontes documentais com contribuições da análise de discurso, orientada por categorias analíticas, em diálogo com as

5 O presente artigo tem como foco a caracterização dessa reação midiática e a abordagem dos elementos evidenciados por ela.

${ }^{6} \mathrm{O}$ arquivo foi preservado por meio do vínculo estabelecido entre a Arquidiocese paulistana, o Núcleo de Documentação e Pesquisa Histórica da Universidade Estadual de Londrina (NDPH-UEL) e com o Laboratório de Estudos das Religiões e Religiosidades (LERR-UEL). Encontrando-se disponível para acesso público em: $<$ http://www.uel.br/grupo-pesquisa/socreligioes/pages/paginas-censuradas-d-o-saopaulo.php>. Acesso em 19/02/2020 
contribuições de Mannheim sobre o pensamento conservador e as correntes de pensamento e de Elias sobre processos de longa e média duração.

Ao dialogar com as contribuições das metodologias citadas, buscou-se desenvolver a interpretação das fontes documentais mobilizadas, tendo em vista o alcance possível a partir do conteúdo das publicações dos jornais e revistas e elementos objetivos que delineavam a conjuntura histórica, social, política e cultural do período no qual as fontes documentais e seu conteúdo foram produzidos.

A análise com fontes documentais foi mobilizada visto que, assim como observa Cellard (2008), ao se trabalhar com fatos passados, os documentos podem ser tomados enquanto testemunhos do período, permitindo acrescentar a dimensão do tempo à compreensão do social. Partindo das considerações feitas por Cellard (2008), a análise das fontes documentais considerou aspectos como o contexto social global no qual as fontes foram produzidas, ou seja, elementos como a conjuntura política, social e cultural, que propiciaram sua concretização.

Buscou-se, então, apreender os esquemas conceituais dos autores e apreender reações, pessoas, grupos, entre outros, aos quais se faz alusão. Destacam-se tais considerações no sentido de se observar que o discurso dos autores, suas ações e intenções presentes em suas elaborações não possuem total autonomia em relação à conjuntura na qual foram produzidos.

As contribuições da análise do discurso foram mobilizadas tendo em vista que, de acordo com Fiorin (1990), as unidades dos discursos constituem sistemas de enunciados, que são significantes, e, dessa forma, 
concernem à história, que justificam as estruturas de sentido que se desenvolvem nos textos. Assim, considera-se que, de acordo com o autor, são relevantes as formas "como o texto diz o que diz, e por que o texto diz o que diz" (FIORIN, 1990, p. 173).

Para Orlandi (2007), o discurso percebe a linguagem como mediação necessária entre os indivíduos e a realidade natural e social, que está incluída no mundo em uma determinada conjuntura que possibilita maneiras de significar e, em tais falas, considera-se a produção de sentido como parte das vidas desses indivíduos enquanto sujeitos e membros de uma determinada forma de sociedade, pois, não há “discurso sem sujeito e não há sujeito sem ideologia: o indivíduo é interpelado em sujeito pela ideologia e é assim que a língua faz sentido” (ORLANDI, 2007, p. 17), ou seja, os discursos não são "neutros".

Considerando tais esclarecimentos, buscou-se desenvolver a interpretação das fontes documentais e dos discursos contidos nessas fontes, tendo em vista também o contexto no qual os indivíduos que as escreveram estavam inseridos e, dessa forma, suas disposições para o agir que foram "ativadas" (LAHIRE, 2002) e que desencadearam reações na mídia impressa de diversos jornais e revistas.

As categorias analíticas que guiaram a interpretação das fontes consistem em apreender: 1) Como pode ser caracterizada a reação midiática ao ato de falsificação? Quais possibilidades a falsificação propiciou em relação à visibilidade de movimentos e ações que buscam sufocar posicionamentos que se choquem com a ideia de manutenção da ditadura militar? Elaboraram-se, a partir dessas categorias, as principais questões que nortearam as interpretações do presente artigo: A falsificação 
do JOSP foi um ato isolado? A reação midiática evidencia elementos que dialogam com o período histórico-político e social no qual está inserida?

A promoção da falsificação do jornal O São Paulo, vinculado a Arquidiocese paulistana, está associada com grupos civis e militares que influenciaram ações oficiais do Estado brasileiro que impôs a censura prévia (1972-1978), bem como, transcendeu em ações paramilitares e civis que geraram formas de violência simbólica e práticas de intolerância religiosa e política. Essa última perspectiva de reação é tradicional e visa impedir o processo de mudança no pensamento social e político católico paulistano da época, bem como, combater o processo de democratização que havia se instalado na sociedade brasileira.

\section{A teologia da libertação e o jornal O São Paulo}

A presente pesquisa guiou-se tendo em vista fatores relativos à conjuntura na qual os elementos abordados pela pesquisa desenvolveramse histórica, social e politicamente. Considera-se, para tal, que as características da formação e do desenvolvimento das relações sócioeconômicas brasileiras (o capitalismo dependente), ${ }^{7}$ e o golpe militar em 1964, ${ }^{8}$ colaboram para o que Rezende (2001) denomina como o

\footnotetext{
7 Ao se falar no desenvolvimento do sistema de produção capitalista no Brasil, a pesquisa dialoga com a perspectiva desenvolvida por Fernandes (1975, p. 337-409), segundo o qual a dependência interna em relação aos interesses político-econômicos externos demandou o desenvolvimento de um rígido sistema político, com baixos níveis de participação democrática, com subsequente tendência à primazia de padrões conservadores e tradicionais de pensamento.

8 De acordo com Mainwaring (2004), a experiência democrática brasileira desenvolvida anteriormente ao golpe militar, tendeu a afastar a sociedade civil mais ampla dos processos políticos decisórios, concentrando essas decisões e esse poder em pequenos agrupamentos.
} 
desenvolvimento de uma "mentalidade" que corroborou com os desígnios dos grupos militares naquele período.

A partir dessa perspectiva e dos documentos disponíveis para a interpretação, foi possível identificar a existência de uma corrente de pensamento que é compreendida como conservadora e que concorreu para as elaborações de visões de mundo ${ }^{9}$ que visavam a manutenção da ordem social do período em questão e dos métodos autoritários dos grupos militares que estavam no poder no decorrer da ditadura militar.

Nesse sentido, é importante observar que o público alvo do jornal abrangia a esfera nacional, não se restringindo à região metropolitana, tendo, dessa forma, considerável público leitor. No decorrer da gestão arcebispal de D. Paulo Arns (Arcebispo da Arquidiocese de São Paulo, cujas falas foram falsificadas no $\mathrm{Mea}$ Culpa), houve um grande salto na quantidade de assinantes do JOSP, chegando, em um breve período, a 50 mil exemplares impressos.

D. Paulo Arns, por exemplo, para além de seu arcebispado, estava articulado com distintos setores nacionais e internacionais, o que lhe possibilitava uma esfera de ação, interligada a outros membros no processo editorial do JOSP, a partir da direção de um meio de comunicação com abrangência considerável no período, lhe proporcionando um local de fala associado com instituições, que potencializavam a ampliação do diálogo entre a Teologia da Libertação (e,

\footnotetext{
9 Weller et al (2002), observam que, para Mannheim, as visões de mundo são o resultado de uma série de vivências ou experiências ligadas a uma estrutura que se constitui como uma base comum das experiências que perpassam a vida de diversos indivíduos, sendo construídas a partir das ações práticas e na totalidade de vivências e/ou experiências que estão interconectadas estruturalmente e que podem derivar da formação de grupos sociais e/ou criações em nível "espiritual".
} 
de forma mais ampla, com o catolicismo) com outras vertentes do pensamento político-social. ${ }^{10}$

Essas especificidades elencam elementos importantes para a análise que considera a conjuntura em questão. No caso de D. Paulo, por exemplo, ao considerar o catolicismo como uma figuração, ressalta-se uma mudança de "foco" de alguns setores do clero da Igreja Católica LatinoAmericana que se voltaram para as massas populares, e, também as orientações advindas do Concílio do Vaticano II (1961-1965), de Medellín (1968) e Puebla (1979).

Dessa forma, dentro das configurações do catolicismo no período $^{11}$, e do arcebispado de D. Paulo, tanto suas ações, como as de outros membros do clero da Arquidiocese de São Paulo e outros movimentos, como foi o caso das Comunidades Eclesiais de Base (CEBs), que naquele período contribuíram para criar um cenário no qual formas de oposição se desenvolveram, são percebidas como formas de resistência à ditadura militar, que convergiram para a proteção aos direitos humanos e a tomada de posicionamentos em tom crítico ao governo ditatorial e a desigualdade econômica.

${ }^{10} \mathrm{O}$ catolicismo nesse período, encontrava-se em um cenário no qual vigoravam no Brasil, entre alguns setores da Igreja, orientações advindas de Puebla e Medellín, além de setores da Igreja e da sociedade civil se engajarem nas lutas pelos direitos humanos. Dessa forma, percebe-se os posicionamentos de D. Paulo em diálogo com toda essa figuração mais ampla, que favorecia um "clima mental", que convergia para a busca por mudanças na ordem social e política do país.

${ }^{11}$ Havia diferentes setores atuando nas Igrejas Católicas, com diferentes orientações e ações. Wanderley (2007) chama a atenção para tal fator ao falar, por exemplo, nos conservadores liderados pelos bispos da Tradição Família e Propriedade (TFP) e em progressistas, representados pelo grupo de Dom Hélder Câmara, que apoiaram as camadas populares e combateram os abusos militares durante a ditadura, assim como lutaram pela redemocratização do país (WANDERLEY, 2007, pp. 26-27). 
Também se considera, em relação à reação midiática desencadeada pela falsificação do JOSP, as observações feitas por Marques de Melo (1982), no sentido de que a forma como a imprensa atua em diferentes momentos da história do Brasil, possui relação com elementos políticos e histórico-sociais desses referidos períodos, com os grupos sociais presentes nesses processos, e com outras características da formação do país. Na perspectiva apresentada pelo autor, a imprensa brasileira, sua permanência e atuação no país, estão relacionadas, portanto, à fatores como os elementos da estrutura social, política e econômica do país, como foi o caso do caráter dependente do capitalismo brasileiro em relação aos interesses das nações capitalistas centrais.

A imprensa, nesse processo, atuou respondendo a elementos que envolvem questões como a configuração do poder político e sua disputa em diferentes períodos políticos e históricos. Contudo, a despeito da tendência presente até o final do século XIX, apontada por Marques de Melo (1982), da imprensa assumir um papel como forma de combate aos adversários políticos e ser um instrumento de pressão junto ao Estado para a obtenção de privilégios, com novas configurações históricas, já nas primeiras décadas do século XX, a imprensa não se configura mais como um meio de comunicação mobilizado exclusivamente por grupos dominantes e passa a ser utilizada, por exemplo, em São Paulo ou no Rio de Janeiro, em publicações avulsas editadas em sindicatos de operários.

Compreende-se o JOSP como um semanário que, a despeito de não ser parte da imprensa independente, imbuído da opção preferencial pelos pobres, pode ser pensado enquanto inserido em um movimento de resistência às medidas totalitárias e desígnios dos grupos militares no 
poder na época, o que se insere em uma movimentação na qual, observa Rosado Nunes (2008), a atuação da Igreja foi um elemento importante na oposição à ditadura militar, pois a Instituição se apresentava como uma das únicas, na sociedade civil, que 'podia 'dar voz pública' à resistência ao regime militar" (ROSADO NUNES, 2008, p. 68).

A partir dessas considerações, os documentos foram separados em três grupos ${ }^{12}$, dos quais o primeiro, composto por documentos referentes ao processo de investigação em si, seu desenvolvimento, questões burocráticas, órgãos mobilizados, e sobre como chegaram aos responsáveis pela edição apócrifa, e o terceiro, composto pelas matérias que contêm informações sobre os envolvidos nesse processo, referindo seus nomes e atribuindo espaços para suas falas ${ }^{13}$. Esta divisão serviu de embasamento para os direcionamentos analíticos da presente proposta.

\section{A edição Mea Culpa pelo prisma da mídia brasileira}

A edição apócrifa corresponde a semana do dia 22 a 26 de agosto, tendo como título a expressão de origem latina $\mathrm{Mea}$ Culpa, cujo significado, de acordo com Polato e Franco de Oliveira (2015), tem sua origem na prece tradicional das missas católicas, a partir da qual o indivíduo praticante $\operatorname{do}(\mathrm{s})$ catolicismo(s) ${ }^{14}$ reconhece seus erros perante Deus.

${ }^{12} \mathrm{O}$ primeiro grupo tem 32 documentos e o terceiro com 82, dos jornais e revistas: Folha de são Paulo, O Estado de São Paulo, Diário Popular, Jornal do Brasil, Hora do Povo, Correio Riograndense, Agência Folhas, O Lutador, O Globo, Voz da Unidade, Boletim da A.B.I., Jornal dos Bairros, Revista Veja e Revista Istoé.

${ }^{13} \mathrm{O}$ segundo grupo contém documentos que veiculavam falas dos membros da Arquidiocese e outros indivíduos a respeito da falsificação.

${ }^{14}$ Compreende-se que, tal como observa Teixeira (2005), não há como situar o catolicismo, no Brasil, em um quadro de homogeneidade, há uma malha diversificada 
Apresenta, por exemplo, admissões de culpa de D. Paulo Evaristo Arns, então arcebispo de São Paulo, por trazer o marxismo para a Igreja, e exposições de diretrizes para os fiéis católicos, pretendendo orientá-los em conformidade e obediência com os desígnios do governo militar do período, fomentando a lógica de vigilância e denúncia dos sujeitos potencialmente subversivos.

Dado o conteúdo da edição Mea Culpa, compreende-se, a falsificação do JOSP como uma manifestação concreta em uma das fases do desenvolvimento de um processo de pensamento conservador brasileiro. Dessa forma, a falsificação do JOSP pode ser analisada como uma ação concreta de grupos vinculados as matrizes do pensamento conservador nacional, que objetivavam intervir diretamente nas configurações da complexidade social do contexto (permeando, assim, um dinâmico embate entre as forças progressistas e conservadoras do momento histórico).

No caso desse grupo falsificador, compreende-se que essa manifestação ocorreu em diálogo com o âmbito religioso referente ao catolicismo, cujo pensamento reflexivo buscava, portanto, conservar a ordem social e política-militar do período. Contudo, no decorrer da pesquisa, apreendeu-se que essas manifestações não se restringiram ao período ditatorial, apresentando outras formas de manifestações em períodos históricos posteriores, como, por exemplo, na contemporaneidade.

de catolicismos, tal como diversas formas de vivência de tal religião. (TEIXEIRA, 2005, p. 17). 
A despeito da tentativa por meio da falsificação de influir sobre a opinião pública, a reação midiática posterior possibilitou a realização de inferências sobre as possíveis consequências dessa falsificação. Com o desenvolvimento das investigações sobre a falsificação e seu acompanhamento pela mídia impressa, as matérias dos jornais foram, também, revelando maiores informações a respeito dos culpados pela falsificação. Apesar de eventuais desencontros entre as informações, o conteúdo das matérias possibilitou uma interpretação que evidenciou elementos relativos, por exemplo, às motivações dos grupos envolvidos na estratégia de confecção e distribuição do jornal falsificado, uma caracterização desses grupos e, também, das ações dos órgãos públicos e privados engajados na investigação.

Alguns dos jornais que acompanharam as investigações, faziam parte do que Azevedo (2006) observou como representantes de uma oposição moderada. Percebe-se isso como um indicativo de que o clima político suscitou não só a possibilidade de que os jornais tivessem mais espaços para noticiar conteúdos que poderiam não ser favoráveis ao governo militar, mas também, dado o clima mental de mudança política, a possibilidade de que editores veiculassem casos como o do $\mathrm{Mea}$ Culpa, pelos quais se poderia estabelecer uma relação entre a falsificação, seu caráter antidemocrático e o apoio de seus autores aos grupos (militares), proporcionando visibilidade pública ao ocorrido

Essa visibilidade e veiculação de notícias ocorreu de forma a abrir espaços para que as próprias ações do governo e seus órgãos investigativos, em seu empenho e interesse em trabalhar o caso, fossem questionados, o que se configura como o oposto ao que se pretendia com 
o Mea Culpa, que era justamente reforçar a importância da continuidade da gestão militar autoritária. A Folha de São Paulo é um exemplo que traz falas do advogado José Carlos Dias (contratado pela Arquidiocese de São Paulo para a investigação da autoria da falsificação), de que o conteúdo do jornal falsificado caracterizava vários crimes do código penal $(\mathrm{S} / \mathrm{N}, \mathrm{A}$ Igreja pede inquérito para apurar fraude. Folha de São Paulo, 25 ago. 1982, p. 1), além de questionar o posicionamento do governo frente ao caso:

Será o governo impotente para descobrir, em dois tempos, os autores das falsificações? Só ingênuos concluirão pela afirmativa. Os serviços gráficos executados não são obra artesanal, de fundo de quintal ou de "aparelhos" clandestinos. [...] Já basta uma rápida leitura para descobrir, por exemplo, a expressão "besta-fera", nova designação da "hidra", que indica a procedência intelectual da falsificação. Esse desesperado método de ação política [...] se constata ser praticado por pessoas que têm completa disponibilidade de tempo e de recursos, além de cobertas por total impunidade ( $\mathrm{S} / \mathrm{N}$, Terrorismo impresso, Folha de São Paulo, 25 ago. 1982, p. 2).

A matéria citada também faz referências, assim como outras publicações, a outros ocorridos, nos quais indivíduos buscaram ou incriminar outros grupos por seus atos, como é o caso do atentado ao Riocentro $^{15}$ (citado em 23 matérias); ou, então, passar por eles, utilizando suas identidades e credibilidade em relação ao seu público a fim de realizar

\footnotetext{
${ }^{15}$ De acordo com Santos (2014), este foi um atentado frustrado que se passou em abril de 1981, no centro de convenções Riocentro, no qual ocorria uma comemoração ao dia do trabalho, cujo show estava sendo promovido pelo Centro Brasil Democrático, organização diretamente vinculada ao Partido Comunista Brasileiro (PCB). Membros do DOI I ex (Destacamento de Operações de Informações do I Exército) compareceram ao evento e plantaram bombas em diversos locais, porém, as explosões ocorreram antes do horário marcado em seu planejamento, e então vitimaram alguns e revelaram outros de seus operacionalizadores, pois após as explosões, pode-se observar que "nas imediações do local, placas de trânsito haviam sido pichadas com a sigla de uma organização revolucionária de esquerda, a Vanguarda Popular Revolucionária" (SANTOS, 2014, p. 04).
} 
comunicados aos leitores, como foi a falsificação do boletim, por exemplo, em nome da $\mathrm{CNBB}$, acusando clérigos de marxistas, e que foi recebido por bispos de todo o país.

Os referidos jornais e revistas veicularam matérias com diversos enfoques a respeito da falsificação do JOSP e de outros atos de adulteração de conteúdo de folhetos ligados às Igrejas Católicas e à ação do clero progressista. Mais do que citar esses casos e levantar possíveis implicações dessas falsificações, acompanharam e relataram as investigações, o que possibilitou a inferência da existência da formulação, por parte dos recursos discursivos utilizados por esses jornais e revistas, de uma correlação entre a busca por respostas sobre a falsificação e a opinião pública.

Por meio das matérias, pode-se apreender que as investigações sobre a falsificação ficaram a cargo do Departamento Estadual de Ordem Política e Social de São Paulo (DEOPS-SP), e com o avançar da acareação de depoimentos e novos elementos, como a localização da gráfica que imprimiu os jornais falsificados em Belo Horizonte, agentes do Departamento de Ordem Política e Social de Minas Gerais (DOPS-MG) e da polícia de Minas Gerais também se envolveram no processo investigativo, nos interrogatórios, e em outros processos que acabaram gerando, inclusive, complicações burocráticas que ocasionaram pausas entre as etapas da investigação. Tais fatores permitem inferir a construção, publicamente, da ideia de que os serviços públicos estariam ou pouco interessados, ou colocando entraves ao desenvolvimento das investigações. 
Um "jogo de empurra" entre o Deops paulista e o Dops mineiro ameaça bloquear as investigações sobre a falsificação do jornal "O São Paulo" apenas 24 horas depois de ter sido descoberta, em Belo Horizonte, a gráfica onde foi impressa a edição apócrifa daquela publicação da Igreja Católica. O Deops de São Paulo diz que as diligências seguintes estão agora a cargo do Dops de Minas, que interrompeu suas investigações afirmando que só as reiniciará se for solicitado (S/N. A polícia sem acordo sobre o jornal falso. Folha de São Paulo, 16 set. 82, p. 1).

A partir do trecho citado, por exemplo, é possível identificar uma referência explícita a questões de ordem burocrática, que representavam possíveis entraves ao processo investigativo devido à responsabilidade atribuída a um departamento e a outro, e pedidos de encaminhamento das investigações a ambos. É importante destacar a afirmação de que um departamento estava tentando atribuir as investigações a outro, em um “jogo de empurra”, expressão a partir da qual se podem inferir, inclusive, questionamentos sobre o empenho dos órgãos públicos no caso. Esse elemento pode ser observado em outras matérias. Por exemplo:

Não fossem as ameaças de Afonso Paulino, na semana passada, que levaram José Calixto a procurar amparo na Igreja e, em seguida, a prestar depoimento à polícia, em São Paulo, muito provavelmente o caso continuaria soterrado na burocracia policial (KOTSCHO, Ricardo. Gráfico aponta falsificador de 'O São Paulo'. Folha de São Paulo, 13 out. 1982, p. 2).

Neste sentido, outro fator que se destaca em ao menos três diferentes matérias, é que a polícia não teria chegado por si própria nem à gráfica na qual foram impressos os jornais falsos, nem aos indivíduos que, em depoimentos, viriam a prestar maiores informações sobre o processo de falsificação e a fornecer os nomes das pessoas envolvidas nesse processo. Informação que se soma aos destaques dados ao engajamento de membros das Igrejas e de seu trabalho conjunto com a imprensa, que 
teriam gerado resultados significativos, informação que é apresentada publicamente com os elementos que fizeram a investigação progredir.

Tais considerações possibilitam refletir sobre a veiculação desses conteúdos como algo que proporcionou aos seus leitores e à opinião pública uma perspectiva de que as investigações dos órgãos públicos somente apresentaram avanços, no espaço de tempo decorrido, devido ao envolvimento da Igreja e da imprensa. Por exemplo:

O inquérito aberto pelo DEOPS deu um grande passo à frente quando graças a uma informação da Comissão de Justiça e Paz da Arquidiocese, localizou-se, em Belo Horizonte, a oficina onde foi impresso o falso jornal (S/N. As edições falsificadas. Boletim da A.B.I., set/out 1982, p. 1).

A forma como essas colocações foram feitas nos jornais evidencia, juntamente a pelo menos quatro outras matérias, a perspectiva de que o trabalho executado pelas autoridades que estavam envolvidas no processo de investigação era questionado em termos de eficiência e, também, de seu interesse em resolver o caso do Mea Culpa e outros casos, como a falsificação de folhetos da Igreja ligados à membros do clero progressista, elemento que foi destacado em cinco matérias.

As referências feitas às falsificações de outros folhetos de elementos ligados ao clero progressista da Igreja Católica evidenciam, ainda, a existência de um movimento contestatório das ações desse segmento progressista e que, no caso das falsificações impressas, espraiava-se por todo o país. A partir das cobranças realizadas pelos jornais, pode-se inferir que os conteúdos dessas falsificações, em diversos casos, dialogaram com elementos pertencentes ao anticomunismo, buscando associar padres, freiras e arcebispos ao comunismo, ao 
marxismo, entre outros. Os grupos envolvidos nessas falsificações, amparados pela falta de investigação e empenho dos órgãos policiais na época, expandiram-se em diversos casos que teriam ficado sem solução.

A matéria do Boletim da A.B.I., por exemplo, fala até mesmo em termos de impunidade em relação às investigações para descobrir os responsáveis por essas falsificações - destacando-se o fato de que a palavra "impunidade" marcou presença em dez matérias diferentes, somando-se a uma referência mais explícita à incompetência apresentada pelos órgãos de investigação em casos como esses:

A impunidade que tem caracterizado tais práticas das forças do obscurantismo no Brasil não autoriza muitas esperanças quanto à descoberta dos responsáveis no caso da edição apócrifa de O São Paulo. Embora existam pistas valiosas para se chegar até eles, é de temer que, a exemplo do caso das bombas do Riocentro, não acabe tudo numa farsa policial, indiciando supostos autores para livrar a cara dos verdadeiros (S/N. As edições falsificadas. Boletim da A.B.I., set/out 1982, p. 1).

É com base em discursos como esse, que se pôde inferir que as matérias nas quais se questiona a ação policial estão associadas à desobstrução paulatina de espaços públicos anteriormente questionados, visto que o momento histórico em que as investigações foram realizadas, na década de 1980, a população e as instituições ainda estavam sob ação da repressão, embora em menor medida, o que incluía ações em prol do combate às suspeitas de envolvimento com o comunismo que podiam apresentar, inclusive, caráter violento.

Casos como o do Riocentro, citado no trecho acima, ilustram a possibilidade de envolvimento de grupos pró-ditadura militar buscando incriminar grupos de outras orientações políticas. Para tal, cometiam ações 
extremas, como o ataque com bombas, e seus responsáveis acabavam ficando impunes, apesar das investigações desenvolvidas.

Essa associação entre um caso e outro, somada às falas do advogado da Arquidiocese de São Paulo, Carlos Dias (ex-presidente da comissão de Justiça e Paz da Arquidiocese de São Paulo), sobre seu receio de que o caso sofresse um processo de "riocentralização" (fala que foi veiculada em cinco edições) são exemplos da associação feita entre a forma de conduzir investigações dos órgãos públicos e uma perspectiva de possível conivência dos órgãos policiais com ações extremas em prol da manutenção da ordem social instaurada nos anos de ditadura militar.

Ao ler as matérias referentes à reação midiática, pode-se perceber que o percurso e os meios para que se chegasse aos resultados apontados, possibilitam inferências acerca do processo de investigação, que, em um primeiro momento, relativamente a outros casos análogos (de falsificação), desenvolveu-se em um espaço de tempo não tão extenso, considerando que os casos anteriores ficaram, de acordo com as fontes documentais utilizadas para a interpretação, sem resolução, resposta pública, ou, ainda, acabaram sendo arquivados.

A primeira matéria contendo, de fato, apontamentos diretos sobre Afonso Araújo Paulino ${ }^{16}$ ser o indivíduo que encomendara a impressão do

\footnotetext{
${ }^{16}$ Os jornais que relataram a autoria de Paulino na falsificação apresentaram-no enquanto editor e proprietário do "Jornal de Minas" e enquanto uma pessoa ligada à extrema direita. Outras edições também apontaram a possibilidade de Paulino ter sido um informante do Serviço Nacional de Informações (SNI), da ID-4 (Quarta Divisão do Exército na década de 1980) e ter sido agraciado com algumas condecorações militares. Além disso, teria processos e acusações públicas de ex-presos políticos por extorsão, tortura, grilagem, sequestro, e 13 processos por crimes de imprensa, meio pelo qual apresentava críticas ao clero progressista e denunciava infiltrações marxistas na Igreja.
} 
JOSP falsificado, foi publicada em 14/10/1982, menos de dois meses após a distribuição da edição apócrifa nas Igrejas em São Paulo. O processo que desencadeou as investigações por parte dos órgãos também não tardou a começar. O início dos debates sobre qual órgão ficaria com as investigações é relatado em matéria publicada do dia 25/09/1982. O início do processo, de fato, teria sido em 26/08/1982, com o inquérito sobre a falsificação sendo instaurado no dia 30 de agosto.

O empresário e proprietário do Jornal de Minas é apontado, em matéria do jornal do Brasil (S/N. Dono de jornal é acusado de falsificar “O São Paulo”. Jornal do Brasil, 13 out. 1982, p. 2), como integrante do Grupo Especial de Trabalho, que, posteriormente, transformou-se em Comissão Geral de Inquérito, e a possibilidade de que ele teria participado do Centro de Operações de Defesa Interna (CODI), e de já ter sido colaborador da Quarta Infantaria Divisionária em Belo Horizonte (ID/4BH). Há também como depoimentos de outros indivíduos, por exemplo, presos políticos, sobre Paulino ser auxiliar de torturas, em 1969, em segmentos dos Destacamentos de Operação Interna (DOI) e dos Centros de Operações e Defesa Interna (CODI) de Belo Horizonte, entre outros.

Apesar de Paulino negar as últimas acusações, afirma, na mesma matéria, sua frequência em círculos militares, até em âmbito mais pessoal, como em jogos de futebol envolvendo os referidos grupos, além de afirmar ser contra a violência e o terrorismo, mas também reafirma um posicionamento de luta ativa contra o comunismo (CASTRO, José. de. Paulino, revolucionário de 64. Jornal do Brasil, 13 out. 1982, p. 2).

A despeito de as matérias não abordarem se, de fato, os indivíduos citados como culpados pela falsificação foram, de alguma forma, 
submetidos a sanções legais, ou se, de fato, as investigações se encerraram com os nomes indicados, um fator se destacou entre os conteúdos das matérias: as investigações foram acompanhadas e detalhadas pelos jornais e, pelo que indicam as matérias, avançaram em relação a outros casos análogos. Dessa forma, pode-se inferir também, que, somadas às medidas e ações do advogado Dias, a cobertura midiática do caso se apresentou, também, como uma forma de "cobrança" pública dos resultados do caso, que associava sua resolução à transparência com a opinião pública.

Compreende-se que isso estaria associado tanto ao fato de que a mídia impressa (e outros meios de comunicação e expressão), com o avanço da abertura política e o fim dos Atos Institucionais, vivia a expansão de espaços de falas para matérias do tipo, quanto com a cobertura midiática ao caso, para o qual se apresentaram cobranças explícitas e públicas por resultados, além de denúncias sobre o descaso dos órgãos policiais e sobre a multiplicação de casos de falsificação dos documentos da Igreja por todo o país.

As diversas referências, por exemplo, às autoridades não estarem (ou estarem pouco) interessadas em resolver o caso (em cinco matérias), ou de que não fosse apurado (quatro matérias), ou, ainda, de que o não progresso da investigação poderia ser algo que desmoralizaria a autoridade e a lei (GOMES, Severo. O crime e a cidadania. Folha de São Paulo, 29 ago.1982, p. 1), aliadas ao fato de que as "vítimas" dessa falsificação foram D. Paulo Arns e a Arquidiocese de São Paulo, são elementos que podem ter influenciado na duração da investigação, no interesse das próprias autoridades em agilizar o processo, dada a opinião pública sobre a atuação do DEOPS-SP, DOPS-MG, da polícia. 
Já as informações a respeito dos responsáveis pela falsificação, possibilitaram refletir a construção, pública, através dos discursos presentes nas matérias, de uma caracterização dos envolvidos nesse processo, sendo apresentados como grupos com recursos materiais (em doze matérias), habilidades para o ato de redigir um texto (em seis matérias) e conhecimentos teológicos (quatro matérias). Tendo em vista os conteúdos elaborados e desenvolvidos no Mea Culpa, também um grupo forte (três matérias) e com organização (quatro matérias).

Para além dessa caracterização, outra possibilidade foi ventilada em oito edições, a de que esses grupos possuíam ou uma orientação política "à direita" ou de "extrema direita" (referida em nove edições) com orientações "radicais", qualidade citada em sete edições. Elemento esse que possibilita reforçar a orientação política desses grupos em diálogo, na realidade, com os grupos militares autoritários e a ordem social instaurada no período ditatorial. Também é possível inferir que pertenciam a um segmento social financeiramente privilegiado - Paulino era um empresário, proprietário de um jornal - que mantinha relações com indivíduos de segmentos militares.

Para além desses fatores, indica-se, também, com base nas falas de Paulino, nos próprios documentos da edição falsificada e no conteúdo da edição $M e a$ Culpa, que esses grupos estabeleciam conexões entre elementos religiosos do catolicismo, com formas de pensamento interligadas aos setores mais conservadores da Igreja, com posições que, abertamente, colocavam-se em franco combate ao comunismo, que era apontado como presente nas ações do clero progressista, não só discordando desse segmento, mas também se chocando com sua forma de inserção nas ações 
sociais com a população. Na folha de São Paulo, por exemplo, é veiculada a seguinte fala:

Afinal, a ação criminosa- a falsificação do órgão da Cúria Metropolitana - tem seus autores individualizados e perfeitamente enquadráveis no Código Penal [...]. O nome da gráfica onde o jornal falsificado foi impresso já é de conhecimento público há muito tempo e agora o encarregado do serviço, José Calixto, que se afirma ameaçado de morte, revela que o autor da encomenda é o empresário mineiro Afonso de Araújo Júnior, de irrepreensível militância em organizações direitistas e proprietário, do "Jornal de Minas", de posições abertamente contrárias à Igreja pós-conciliar (S/N. Crime sem castigo. Folha de São Paulo, 14 out. 1982, p. 1).

O Mea Culpa e seu conteúdo desencadearam, portanto, uma reação midiática, que se mostrou contrária ao que seus autores pretendiam, atribuindo destaque às características marcadamente políticas da falsificação, envolvendo as visões de mundo contidas na edição. Essas características não passaram despercebidas nas publicações referentes à reação midiática, que aborda em sete matérias, que não só a falsificação do JOSP, mas outros atos nesse sentido, tinham relação com a conjuntura política da época e colocavam-se contra a democracia, buscando, com isso, dificultar o processo de transição política.

Entre outras razões atribuídas à falsificação, citadas mais de uma vez nos documentos da reação midiática, encontram-se: o objetivo de confundir o povo e os leitores do JOSP (citado em doze matérias), de criar conflitos internos entre membros do clero (duas edições), desmoralizar D. Paulo (duas edições) e, ainda, enganar o povo (três edições).

Para além desse fator, a leitura de seus documentos também evidenciou que, ao se aperceberem da distribuição das edições falsas, os próprios membros das Igrejas passaram a avisar outras Igrejas, e logo os 
órgãos públicos foram envolvidos no caso. Isso ganhou notoriedade nos jornais que o acompanhavam e acabou não só abrindo espaços para se falar publicamente da existência de todo um movimento que reagia à abertura política em curso no país e que mantinha diálogos com correntes de pensamento associadas ao governo ditatorial, mas também atribuindo notoriedade pública à existência de articulações que visavam manipular a opinião pública.

Pelo menos dezenove edições fazem alusão a esse fator, através de falas e termos como: existência de falsificações pelo país (uma edição), atos semelhantes (uma edição), onda de falsificação de documentos da Igreja (uma edição), avalanche das falsificações (uma edição), campanha orquestrada/organizada (sete edições), campanha por todo o país (oito edições). Essa incidência possibilitou a formação de uma representação da falsificação do JOSP como algo que não se restringia à Arquidiocese de São Paulo e D. Paulo Arns, mas como uma forma de ataque frontal às Igrejas Católicas de todo o país, por se tratar de um movimento que se expandia a todo o território nacional e que poderia crescer ainda mais.

A reação midiática possibilitou que se ressaltassem e evidenciassem, em diversos meios de comunicação, características desses movimentos de falsificação, assim como seu objetivo de manipular a opinião pública e os artifícios utilizados por esses grupos. As matérias citam diversos outros casos de ações que visavam a manipulação da opinião pública através da mobilização de elementos religiosos contra membros do clero católico; Em Uberaba foi a cartilha política de D. Benedito Ulhoa Vieira (citada em quatro edições). No Rio de Janeiro, uma cartilha do cardeal Eugênio Salles (catorze matérias), a falsificação de uma 
matéria do padre Paul-Egèune Charbounneau (referida em quatro edições) e o já citado Riocentro (vinte e três edições). Outros ocorridos também são citados, como os atentados a bancas de jornal com bombas (sete edições), o panfleto "O Anti-Cristo" (cinco matérias), a violação e troca de conteúdo de correspondências entre freiras, nas quais se faziam associações entre padres e comunismo (episódio citado em dezessete edições), o boletim semanal da CNBB que foi falsificado (doze edições), entre outras.

As matérias também possibilitam pensar a existência da construção pública de uma da caracterização dessas estratégias enquanto antidemocráticas e criminosas. Em matéria, por exemplo, do Estado de São Paulo, são feitas alusões às falsificações como atos de terrorismo:

\footnotetext{
Ainda ontem, o Sindicato dos Jornalistas Profissionais de São Paulo divulgou nota solidarizando-se com o cardeal- arcebispo da cidade e repudiando o "ato de terrorismo que vem se somar a muitos outros", segundo a nota "cometidos por aqueles que, pretendem impedir a caminhada do povo brasileiro para a democracia" (S/N. O jornal falso chega ao Pará. O Estado de São Paulo, 20 out. 1982, p. 1).
}

As publicações da reação midiática, portanto, evidenciaram e atribuíram notoriedade ao caráter criminoso dos atos de falsificação, o que incluiu referências a implicações legais que caracterizam a confecção dessa edição do jornal como uma ação criminosa, ou obra de criminosos (termos citados em doze matérias), além das referências feitas às infrações à legislação, como crimes de falsidade material, falsificação de documento particular, injúria, calúnia e difamação, que reforçam essa caracterização em termos legais.

\section{Considerações Finais}


A reação dos meios de comunicação impressos que se seguiu à falsificação do jornal O São Paulo foi compreendida, pela abordagem e interpretação propostas, como algo pertinente ao momento histórico, cenário social e político no qual o processo de redemocratização já estava se encaminhando e se desenvolvendo, o que abria espaços de expressão anteriormente congestionados pelas medidas governamentais autoritárias a, justamente, controlar e censurar o fluxo de informações e manifestações contrárias aos grupos militares que estavam no poder.

A respectiva reação midiática, nesse sentido, é característica de um período no qual a cena pública e o campo político estavam sendo paulatinamente desobstruídos para outras agendas políticas e culturais que não somente aquelas associadas aos grupos militares, sua continuidade no poder e seus desígnios. Em meio a esse movimento de redemocratização, a reação midiática teria tido ocasião de acompanhar as investigações, cobrar e questionar órgãos públicos de segurança e investigação.

No início da década de 1980 em que a reação midiática ocorreu, já se haviam passado os anos mais rígidos de censura à imprensa e a outros meios de comunicação. Contudo, isso não implicava a não existência de ações estratégicas antidemocráticas dos grupos que dialogavam com correntes de pensamento conservadoras, como método de permanência frente ao processo de redemocratização, como foi o caso do Mea Culpa.

Partindo da noção de que a falsificação suscitou reações contrárias ao seu objetivo, que era a manutenção da ditadura, compreende-se que acabou sendo um elemento que contribuiu para desencadear disposições nos grupos responsáveis pelos jornais que acompanharam as investigações 
para ocuparem espaços abertos pelo processo de transição política, que permitia maior "liberdade" em publicar conteúdos que se desencontravam das perspectivas de manutenção da ditadura militar.

Naquele período as ações dos grupos pró continuidade da ditadura militar - como os responsáveis pelo Mea Culpa e pelo atentando do Riocentro - buscavam intervir na opinião pública, manipulando-a e ganhando certa notoriedade. No entanto, a elucidação de seus objetivos e a caracterização de suas estratégias permite identificá-los enquanto atos criminosos e anti-democráticos.

Nota-se que a dinâmica das disputas entre grupos políticos na conjuntura do período demarcou-se em distintas formas de exacerbação do combate ao comunismo, inclusive incorrendo em ações persecutórias aos grupos potencialmente progressistas que, em alguns casos, se configuravam de formas altamente violentas. Se por um lado as transformações da realidade social brasileira, e latino-americana, influenciaram uma mudança de posicionamento na visão de mundo do clero que passou à se vincular à Teologia da Libertação, por outro, as mesmas condicionalidades, assim com o próprio surgimento desta vertente católica libertadora, influíram em novas medidas e articulações dos grupos tradicionais e conservadores na realidade brasileira.

O combate a mudança de perspectiva religiosa do clero libertador se delineou de múltiplas maneiras: institucional legitimada, à exemplo da imposição da censura prévia; institucional pública, principalmente por meio do combate aberto em meios de comunicação; e atentados criminosos ilegítimos, como a falsificação do jornal O São Paulo, os atentados, sequestros e assassinatos de membros e adeptos da Teologia da 
Libertação, entre tantos outros fatos que tomaram forma na realidade ditatorial militar brasileira (1964-1985).

\section{Referências bibliográficas}

AZEVEDO, F. A. Mídia e democracia no Brasil: relações entre o sistema de mídia e o sistema político. Opinião Pública, Campinas, v. 12, n. 1, pp. 88-113, maio, 2006.

CELLARD, A. A análise documental. In: POUPART, J. et al. A pesquisa qualitativa: enfoques epistemológicos e metodológicos. Petrópolis: Vozes, 2008.

DELLA CAVA, R. A Igreja e a Abertura, 1974-1985. In: KRISCHKE, P.; MAINWARING, S. (Orgs.). A Igreja nas bases em tempo de transição (1974-1985). Porto Alegre: L\&PM/CEDEC, 1986.

ELIAS, N. Norbert Elias por Ele mesmo. Rio de Janeiro: Jorge Zahar, 2002.

FERNANDES, F. A Revolução Burguesa no Brasil. Rio de Janeiro: Zahar Editores, 1975.

FIORIN, J. L. Tendências da análise do discurso. Cadernos de Estudos Linguísticos, Campinas, v. 19, pp. 173-179, 1990. Acesso em: <https://periodicos.sbu.unicamp.br/ojs/index.php/cel/article/view/86 36834>. Acesso em: 01 nov. 2018.

FONSECA JUNIOR., W. C. da. Análise de Conteúdo. In: DUARTE, J.; BARROS, Antônio (Orgs.). Métodos e Técnicas de Pesquisa em Comunicação. 2. Ed. São Paulo: Atlas, 2009.

KRISCHKE, P.; MAINWARING, S. (Orgs.). A Igreja nas bases em tempo de transição (1974-1985). Porto Alegre: L\&PM/CEDEC, 1986.

LAHIRE, B. Homem plural: os determinantes da ação. Trad. Jaime A. Clasen. Petrópolis: Vozes, 2002

LANZA, F. Matrizes Ideológicas dos Arcebispos Paulistanos (195685): um olhar sob o prisma do semanário O São Paulo. 2006. Tese 
(Doutorado em Ciências Sociais) - Pontifícia Universidade Católica de São Paulo, São Paulo, 2006.

MAINWARING, S. Igreja Católica e política no Brasil (1916-1985). São Paulo: Brasiliense, 2004.

MANNHEIM, K. O pensamento conservador. In: MARTINS, J. S. (org.). Introdução crítica à sociologia rural. São Paulo: Hucitec, 1981.

MARQUES DE MELO, J. de. Brasil: Imprensa e capitalismo dependente. Cadernos Intercom, São Paulo, ano 1, n. ${ }^{\circ}$ 3, pp. 70-79, 1982.

MONTERO, P.; DELLA CAVA, R. A Igreja Católica e os meios de comunicação de massa. In: Religião e Sociedade, Rio de Janeiro, v. 13, n. 3, pp. 63-74, 1986.

NEVES, M. H. de M. Guia de uso do Português: confrontando regras e Usos. São Paulo: Ed. da UNESP, 2003.

ORLANDI, E. P. Análise de Discurso: princípios e procedimentos. $7^{\circ}$ Ed., Campinas, SP: Pontes, 2007.

POLATO, A. D. M.; FRANCO DE OLIVEIRA, N. A. Gênero notícia: movimentos discursivizados nos limites entre informação e opinião. Fórum Linguístico, Florianópolis, v. 12, n. 1, pp. 579-594, 2015.

REZENDE, M. J. de. A ditadura militar no Brasil: Repressão e Pretensão de legitimidade 1964-1984. Londrina: Editora UEL, 2001.

RODRIGUES, R. R. B. Permanências do conservadorismo brasileiro no processo de redemocratização na década de 1980: estudo d'O São Paulo e da edição falsificada mea culpa. Dissertação (Mestrado em Ciências Sociais) - Universidade Estadual de Londrina, Centro de Letras e Ciências Humanas, Programa de Pós-Graduação em Ciências Sociais, 2018.

ROSADO NUNES, M. J. Direitos, cidadania das mulheres e religião. In: Tempo Social, revista de sociologia da USP, v. 20, n. 2, nov. 2008. pp. 67-81.

SANTOS, V. G. R. dos. Caso Riocentro: Terror e violência no processo de abertura política brasileiro. Revista Contemporânea. Niterói, Ano 4, v.1, n. 5, pp. 1-27, 2014. TEIXEIRA, F. Faces Do Catolicismo Brasileiro 
Contemporâneo. Revista USP, São Paulo, n. 67, pp. 14-23, set./nov. 2005.

WANDERLEY, L. E. W. Democracia e Igreja Popular. São Paulo: EDUC, 2007.

WELLER, W. et al. Karl Mannheim e o método documentário de interpretação: uma forma de análise das visões de mundo. Sociedade e Estado, Brasília, 2002, v. 17, n. 2.

\section{Referências Documentais}

CASTRO, J. de. Paulino, revolucionário de 64. Jornal do Brasil, 13 out. 1982, p. 2.

GOMES, S. O crime e a cidadania. Folha de São Paulo, 29 ago. 1982, p. 1.

KOTSCHO, R. Gráfico aponta falsificador de 'O São Paulo'. Folha de São Paulo, 13 out. 1982, p. 2.

S/N. As edições falsificadas. Boletim da A.B.I., set./out. 1982, p. 1.

S/N. O jornal falso chega ao Pará. O Estado de São Paulo, 20 ago.1982, p. 1.

S/N, A Igreja pede inquérito para apurar fraude. Folha de São Paulo, 25 ago. 1982 , p. 1.

S/N, Terrorismo impresso, Folha de São Paulo, 25 ago. 1982, p. 2.

S/N. A polícia sem acordo sobre o jornal falso. Folha de São Paulo, 16 set. 82, p. 1.

S/N. Dono de jornal é acusado de falsificar "O São Paulo". Jornal do Brasil, 13 out. 1982, p. 2.

S/N. Crime sem castigo. Folha de São Paulo, 14 out. 1982, p. 1. 